\title{
Fermentation strategy to produce high gluconate vinegar
}

\author{
Paolo Giudici, Luciana De Vero, Maria Gullo, Lisa Solieri, Federico Lemmetti \\ Department of Life Sciences, Unimore Microbial Culture Collection, University of Modena and \\ Reggio Emilia, Italy
}

\begin{abstract}
Gluconic acid is a non-volatile acid that has many applications in food, pharmaceutical and cleaning fields. Gluconic acid has been detected as main oxidation product of Acetobacter and Gluconobacter strains growing on grape must, and it plays an important role in Traditional Balsamic Vinegar. Commonly, high gluconate vinegars have a greater physical stability and a greater preference by consumers because are perceived less pungent. In fact, gluconic acid reduces the $\mathrm{pH}$ and increases fixed acidity of the vinegar without increasing the sensation of pungency typical of acetic acid. Its taste is acid but mild sweet and, therefore, gluconic acid has influence on the sensory complexity of the vinegar. The aim of this work is to set up a fermentation procedure that improves the quality of balsamic vinegar by using selected yeasts and acetic acid bacteria strains able to oxidize glucose in grape must-based media having a different sugars concentration. In particular, Saccharomycodes ludwigii UMCC 297 and Acetobacter pasteurianus UMCC 1754 strains were chosen as selected starter cultures for small-scale fermentation of cooked grape must, to evaluate the physical-chemical parameters affecting gluconic acid production in the obtained vinegar. The strains used and the control of all production process have been fundamental for obtaining the vinegar with the desired characteristics.
\end{abstract}

Correspondence: Paolo Giudici, Department of Life Sciences, University of Modena and Reggio Emilia, via Giovanni Amendola 2, 42122 Reggio Emilia, Italy.

Tel.: +39.0522522034 - Fax: +39.0522522027 .

E-mail: paolo.giudici@unimore.it

Key words: Gluconate producing acetic acid bacteria; ethanol catabolic repression; osmotolerant glucophilic yeasts.

Contributions: PG conceives the paper; PG, LDV and MG contribute to collect and analyze the data; PG, LDV, FL and LS write and discuss the manuscript.

Conflict of interest: the authors declare no conflict of interest.

Received for publication: 7 June 2016.

Revision received: 18 August 2016.

Accepted for publication: 18 August 2016.

This work is licensed under a Creative Commons Attribution NonCommercial 4.0 License (CC BY-NC 4.0).

(C) Copyright P. Giudici et al., 2016

Licensee PAGEPress, Italy

Acetic Acid Bacteria 2016; 5:6067

doi:10.4081/aab.2016.6067

\section{Introduction}

Traditional Balsamic Vinegar (TBV) should not be confused with Balsamic Vinegar of Modena or with any other vinegars or sauces having similar name, because it has a completely different and peculiar manufacturing procedure; a clear explanation about "balsamics" and their relative production process was previously reported. ${ }^{1}$ In short, TBV is produced starting from grape must that is concentrated by heating in open vessel, then the cooked must is partially fermented to base wine (BW) with $6-8 \%(\mathrm{v} / \mathrm{v})$ of ethanol and 15$25 \%(\mathrm{w} / \mathrm{v})$ of residual sugars, then ethanol is oxidized to acetic acid by acetic acid bacteria (AAB). The resulting base vinegar is finally aged and concentrated for several years in a set of 5 or more barrels, using a Solera-like method. The final "gross composition" of TBV is a vinegar with around $40 \%$ (w/v) of sugars, mainly glucose and fructose in 1:1 ratio; $2-5 \%$ (w/v) of acetic acid; $5-10 \%$ (w/v expressed as acetic acid) of titratable acidity; $\mathrm{pH}$ of $2.3-3.2 .^{2}$

Recent studies showed that TBV having sugar concentration (sum of glucose and fructose) over 50\% (w/v) and ${ }^{\circ}$ Brix values over 70 may undergo extensive solidification phenomena through equilibrium and out-of-equilibrium mechanisms, with a shift in flow properties from Newtonian to shear-thinning rheological behavior. ${ }^{3}$ An attempt to identify both the chemical and physical properties of the bulk of the solidified vinegars has been made by coupling different approaches: (i) microbiological to enzymatic techniques; ${ }^{4}$ (ii) highresolution light microscopy to X-ray diffractometry; ${ }^{5}$ (iii) size-exclusion liquid chromatography to environmental scanning electronic microscopy; (iv) energy dispersive X-ray spectroscopy and rheology. ${ }^{6}$ Data provided striking evidences for the simultaneous presence of a crystalline structures and a jammed phase. In particular, crystallized phase consists of $\alpha$-D-glucose monohydrate molecules and jamming is caused by the crowding of amorphous colloids. Sugarderived melanoidins were supposed to play a role in developing colloidal bulk structure of the vinegar and, eventually, into its solid network extension. ${ }^{7}$

Yeasts carrying out the spontaneous fermentation of TBV are mainly osmotolerant species able to survive and grow under the high osmotic pressure of the concentrated (cooked) grape must, which in some cases can reach more than $70{ }^{\circ}$ Brix of soluble solids. ${ }^{8}$ The most frequently isolated species are Zygosaccharomyces bailii, Zygosaccharomyces rouxii, Zygosaccharomyces pseudorouxii, Zygosaccharomyces mellis, Zygosaccharomyces bisporus, Zygosaccharomyces lentus, Zygosaccharomyces sapae, Hanseniaspora valbyensis, Hanseniaspora osmophila, Candida lactis-condensi, Candida stellata, Saccharomycodes ludwigii and Saccharomyces cerevisiae..$^{9,10}$ The majority of these species are fructophilic yeasts, which consume preferentially fructose than glucose, a behavior opposite to that of Saccharomyces cerevisiae. ${ }^{11}$ Therefore, when fructophilic yeasts grow on an equimolar solution of glucose and fructose, like grape must, they ferment fructose, leaving the glucose at high concentrations. ${ }^{12}$ This fructophilic behavior relies on the pat- 
tern of glucose and fructose transporters, which prioritize the fructose transport over that of glucose. For example, $Z$. rouxii and $Z$. bailii possess two different systems for fructose uptake: a fructosespecific facilitator with high capacity and low affinity; and a lowcapacity and high-affinity facilitator that also transports glucose but it is inactivated at high fructose concentrations. ${ }^{13,14}$ Other less osmotolerant species, such as $S$. ludwigii, seem to be more similar to $S$. cerevisiae and moderately prefer glucose over fructose. Glucose transport mechanisms have been extensively studied in $S$. cerevisiae ${ }^{15}$ but they have been not yet characterized in other glucophilic yeasts. Osmophilic yeasts ferment cooked must to BW, which contain residual sugars (200-300 g/L, mainly glucose and fructose), ethanol $(<7 \% \mathrm{v} / \mathrm{v})$, minor or secondary products of alcoholic fermentation (glycerol, succinate, higher alcohols), other than the main organic acids of grapes. ${ }^{16}$ All these compounds have hydroxyl or aldehyde functional groups that are potentially oxidized by AAB. In particular, glucose can be oxidized to gluconic acid, also known as "the acid of glucose", and its derivatives have many applications in food, pharmaceutical and cleaning products. ${ }^{17}$ The inner-ester form (glucono- $\delta$-lactone) is used as acidulant, flavoring and leavening agent in baked and dairy products; calcium and iron salts are used as mineral supplements, sodium salt is a cleaning agent due to its chelating capability.

Glucono- $\delta$-lactone plays an important role in TBV: it has influence on the sensorial properties (Giudici et al., unpublished data), it reduces the $\mathrm{pH}$ and increases fixed acidity. ${ }^{18}$

$\mathrm{AAB}$ oxidize sugars and alcohols by primary dehydrogenases located on the outer surface of citoplasmatic membrane. They include many specific pyrrolo-quinoline quinone (PQQ)-dependent dehydrogenases (quinoproteins and quinoprotein-cytochrome c complexes) and flavin adenine dinucleotide (FAD)-dependent dehydrogenases (flavoprotein-cytochrome c complexes). ${ }^{19}$ Further intermediate oxidation and substrates assimilation occur at cytoplasmic site by the cytosolic NAD(P)-dependent oxidoreductases. ${ }^{20}$ In Acetobacter, Gluconacetobacter and Komagataeibacter species ethanol oxidation mainly leads to acetic acid accumulation via acetaldehyde, through the sequential reactions of the membrane-bound PQQ-dependent alcohol dehydrogenase (ADH) and aldehyde dehydrogenase (ALDH). After ethanol depletion, acetate accumulates into the cytosol and can be utilized by the cell via acetyl-CoA synthase and phosphoenolpyruvate carboxylase. ${ }^{20}$ Glucose oxidation, which generates a considerable number of metabolites, is well studied in Gluconobacter oxydans. $^{21}$ The most characteristic reaction is the direct oxidation to glucono- $\delta$-lactone by glucose dehydrogenase (GDH), which can be hydrolyzed into D-gluconate by a membrane-gluconolactonase. ${ }^{22}$ Depending on the $\mathrm{pH}$ of the medium, D-gluconate is further oxidized to 2-ketogluconate and 2,5-diketogluconate by the gluconate dehydrogenase and 2-ketogluconate dehydrogenase, respectively. ${ }^{23}$ Gluconic acid has been previously detected as main oxidation product of Acetobacter and Gluconobacter strains growing on grape must, ${ }^{24}$ and it is also proposed as indicator of TBV genuineness. ${ }^{18}$

Oxidation of alcohols and sugars by AAB is well studied in defined media, while less data are available on complex media, where both alcohols and sugars are the major carbon sources; this is the case of the acidification of wine base for TBV.

The aim of this work is to set up a fermentation procedure that improves the quality of TBV by the use of selected yeast and AAB strains able to oxidize glucose in complex media. In particular, our hypothesis is based on two evidences: i) yeasts show selective preference for glucose or fructose; ii) the direct oxidation of glucose by $\mathrm{AAB}$ could contribute to reduce the glucose content of the final vinegar, to increase its fixed acidity and to enhance its sensorial properties.

\section{Materials and Methods}

\section{Microorganisms and culture conditions}

Six yeast strains isolated from TBV in different years were chosen for their ability to grow on high sugary media and for their differential preference for glucose or fructose. ${ }^{25}$ Four osmotolerant strains belong to Z. bailii (UMCC 70=ABT1301), Z. sapae (UMCC 152=ABT301), Z. bisporus (UMCC 61=ABT1101) and $C$. stellata (UMCC 122=ABT503) species, respectively, while 2 strains belong to $S$. ludwigii species (UMCC 294=B8805 and UMCC 297=B8815). Saccharomyces cerevisiae strain UMCC 855 (=21T2) was used as reference for its oenological suitability. ${ }^{26,27}$ Yeast cultures were routinely maintained at $4{ }^{\circ} \mathrm{C}$ on YPD medium (1\% yeast extract, $2 \%$ peptone, $2 \%$ glucose) supplemented with $2 \%$ agar when required. Yeasts were pre-cultured at $24^{\circ} \mathrm{C}$ for $24 \mathrm{~h}$ (S. cerevisiae) or $48 \mathrm{~h}$ (non-Saccharomyces strains) in Erlenmeyer flasks filled with the same medium used for the corresponding fermentation trial. One AAB strain UMCC 1754 (=AB0220=DSM 25273), belonging to A. pasteurianus species, was selected for its good performances in submerged and static fermentation. The evolution of AAB during the fermentation process was followed with the method previously described by Gullo et al. ${ }^{28,29}$

All the strains are deposited at the Unimore Microbial Culture Collection (UMCC, www.umcc.unimore.it)).

\section{Fresh grape and cooked must used for fermentation trials}

Three grape must-based media were used: 1) Medium 1 (M1) is a fresh grape must (white grape cultivar Trebbiano: Vitis vinifera) having $200 \mathrm{~g} / \mathrm{L}$ of sugars, pH 3.22 and titratable acidity $9.00 \mathrm{~g} / \mathrm{L}$ (expressed as tartaric acid); 2) Medium 2 (M2) is a fresh grape must added with glucose and fructose (ratio 1/1) to reach $400 \mathrm{~g} / \mathrm{L}$ of sugars; 3 ) Medium 3 (M3) is cooked must, obtained from fresh grape must concentrated by direct heating following the procedure previously described. ${ }^{5}$

\section{Laboratory-scale alcoholic fermentation}

Two sets of laboratory fermentation trials were carried out with fresh grape must M1 and M2 (200 g/L and $400 \mathrm{~g} / \mathrm{L}$ of sugars, respectively). Each fermentation experiment was done in triplicate under static conditions. For each trial, $250 \mathrm{~mL}$ Erlenmeyer flasks were filled with 200 $\mathrm{mL}$ of the appropriate grape must and inoculated with $10 \mathrm{~mL}$ of each pre-culture yeast. Each flask was covered with $5 \mathrm{~mL}$ of liquid paraffin to avoid the contact with air and incubated at $20^{\circ} \mathrm{C}$. The fermentation trials were carried out until the weight of the vials did not change over 24 hours. The vials were stored in refrigerator $\left(4^{\circ} \mathrm{C}\right)$ until the lees completely settle down, and then the wines were withdrawn and analyzed.

\section{Small scale cooked must alcoholic fermentation}

A vat of $500 \mathrm{~L}$ of cooked must (M3) was inoculated with $25 \mathrm{~L}$ of a preculture of $S$. ludwigii strain UMCC 297 reaching the final cell density of around $10^{7} \mathrm{cel} / \mathrm{mL}$. The total volume $(25 \mathrm{~L})$ of pre-culture was obtained starting from $200 \mathrm{~mL}$ of $\mathrm{M} 3$, sterilized through a 0.2 - m pore filter unit (Nalgene, Rochester, NY), inoculated with a loop of cells directly from the agar slant, then the culture was added every 48 hours with increasing amount of the same sterile medium. The fermentation was carried out until the ethanol reached a concentration between $6-7 \%(\mathrm{v} / \mathrm{v})$, then the fermentation was stopped by filtration and the resulting BW was cold-preserved until the subsequent acetic acid fermentation.

\section{Acetic acid fermentation}

The acetic acid fermentation was performed in static condition: three wood barrels $(60 \mathrm{~L})$ were filled for $2 / 3$ of the volume of their 
capacity (to leave head space over a large liquid surface) with the BW inoculated with a starter culture of $A$. pasteurianus UMCC 1754 strain. The laboratory scale of UMCC 1754 strain was prepared on the same BW, following the procedure reported by Gullo et al. ${ }^{28}$ The acetification process was monitored by determination of both ethanol amount and titratable acidity as described below.

\section{Analytical determination}

Base wine samples and vinegars were characterized for reducing sugars by the Fehling method ${ }^{30}$ and titratable acidity by acid-base titration. pH was measured with a Crison $2002 \mathrm{pHmeter}$. Glucose, fructose, lactic acid, glycerol, acetic acid, acetaldehyde, gluconic acid, glucono$\delta$-lactone, succinic acid, malic acid and ethanol contents were determined using the enzymatic kits (Megazyme, Bray, Ireland), according to manufacturer's instructions.

\section{Results and discussion}

\section{Alcoholic fermentation trials}

As a first selection step six different yeasts were evaluated for their fermentative features in two grape musts (M1 and M2) differing in sugar content. In M1 each strain showed a different fermentation behavior with regard to malic acid consumption and the amount of ethanol, glycerol and succinic acid produced. Zygosaccharomyces strains produced higher level of succinic acid and consumed less malic acid, with a major effect on the titratable acidity of the resulting BW (Table 1). As the secondary products of alcoholic fermentation are potential substrates for $A A B,{ }^{22,31}$ their amount can affect the quality of the vinegar. However, as far as we know, there are no data on direct relationship between sensory properties of vinegar and minority products of alcoholic fermentation. Although the topic is intriguing, it will be the subject of future researches, as the main purpose of this work is to evaluate the preferential consumption of the two hexoses in the must. The data clearly show that the strains belonging to the osmotolerant species Z. bailii, Z. sapae, Z. bisporus and $C$. stellata exhibit a preferential consumption for fructose. In particular, the strain of $C$. Stellata depleted completely the fructose and left $53 \mathrm{~g} / \mathrm{L}$ of glucose at the end of fermentation. In contrast, neither $S$. ludwigii or $S$. cerevisiae consumed almost completely the sugars, leaving only limited amounts of fructose in the medium. These results agree with the literature, where the preferential consumption of fructose is reported to be dependent on different mechanisms of transport of the sugars and it is frequently associated with the osmotolerance..$^{11,14}$

Given that $S$. ludwigii strains UMCC 294 and UMCC 297 completely consumed both sugars, we could not properly evaluate their sugar preference. Therefore, a second round of fermentation trials was carried out in must (M2) at higher sugar concentration (400 g/L) using the same strains as starter cultures. We choose the $S$. ludwigii strains for three main reasons: i) they led to a titratable acidity higher than those obtained with $S$. cerevisiae in the previous trials; ii) the resistance to acetic acid of the species $S$. ludwigii is higher than that of other species of oenological interest ${ }^{32}$; iii) the tolerance to acetic acid is an interesting character for the fermentation of partially acidified must.

The M2 sugar concentration is the upper limit in common must fermentation for the production of TBV, where to stop the fermentation before the complete depletion of sugars is very important. ${ }^{16}$ The result of the second alcoholic fermentation trials is reported in Table 2. At the end of fermentation, the amount of ethanol produced by the two $S$. ludwigii strains, UMCC 294 and UMCC 297, was 3.8\% and 4.6\% (v/v), respectively. The observed values are lower than the optimal ones (6$7 \%$ ) for the production of TBV. In fact, the concentration of sugars was slightly higher than the optimum for the production of TBV, which must be less than $350 \mathrm{~g} / \mathrm{L} .{ }^{7}$ As expected, both strains preferentially assimilated glucose. Consequently, at the end of fermentation, the difference between the concentrations of the two sugars was next to $30 \mathrm{~g} / \mathrm{L}$ in favor of fructose. The glucose/fructose ratio, starting from 1 in concentrated grape must, decreased to 0.81 and 0.76 for the strains UMCC 294 and UMCC 297, respectively. The UMCC 297 strain showed the higher production of ethanol, the minor variability in the three replicas and the minor glucose/fructose ratio, therefore it was chosen for the production in larger scale of BW from cooked must.

\section{Small scale alcoholic fermentation - base wine prepa- ration}

The fermentation of $500 \mathrm{~L}$ of cooked must (M3), inoculated with the starter culture of $S$. ludwigii strain UMCC 297, was regular and required three weeks to reach $6.35 \%(\mathrm{v} / \mathrm{v})$. In Table 3 the composition of $\mathrm{M} 3$ and the resulting BW is detailed. The ethanol production arises for the most part from the consumption of glucose, which significantly decreased from $168.4 \mathrm{~g} / \mathrm{L}$ to $97.1 \mathrm{~g} / \mathrm{L}$, while the concentration of fructose was higher than $110 \mathrm{~g} / \mathrm{L}$.

In fresh must the glucose/fructose ratio is 1 , while it increases to 1.08 in cooked must due to the cooking process where fructose degrades faster than glucose. ${ }^{5}$ At the end of the fermentation of the cooked must, carried out with the yeast strain UMCC 297, the glucose over fructose ratio reverse in favor of fructose (Glucose/Fructose=0.82). Therefore, the reduction of the glucose/fructose ratio in small-scale trials was even higher than those of laboratory trials. The test clearly demonstrates that the use of selected yeast strain for the alcoholic fermentation can lead to BW with high fructose content.

Table 1. Base wine composition after fermentation of medium M1 (200 g/L of sugars) by osmotolerant strains isolated from Traditional Balsamic Vinegars.

\begin{tabular}{|c|c|c|c|c|c|c|c|c|c|c|}
\hline Species & Strains code & $\mathrm{pH}$ & TA* & $\begin{array}{l}\text { Malic acid } \\
\mathrm{g} / \mathrm{L}\end{array}$ & $\begin{array}{l}\text { Succinic acid } \\
\mathrm{g} / \mathrm{L}\end{array}$ & $\begin{array}{l}\text { Acetic acid } \\
\mathrm{g} / \mathrm{L}\end{array}$ & $\begin{array}{l}\text { Glycerol } \\
\mathrm{g} / \mathrm{L}\end{array}$ & $\begin{array}{l}\text { D-Glucose } \\
\mathrm{g} / \mathrm{L}\end{array}$ & $\begin{array}{c}\text { D-Fructose } \\
\mathrm{g} / \mathrm{L}\end{array}$ & $\begin{array}{l}\text { Ethanol } \\
\% \mathrm{v} / \mathrm{v}\end{array}$ \\
\hline Z. bailii & UMCC 70 & $3.22^{c}$ & $9.91^{\mathrm{a}}$ & $1.59^{\mathrm{d}}$ & $1.49^{c}$ & $0.24^{c}$ & $4.25^{\mathrm{a}}$ & $33.13^{b}$ & $0.30^{\mathrm{a}}$ & $8.90^{c}$ \\
\hline Z. sapae & UMCC 152 & $3.18^{\mathrm{ab}}$ & $9.63^{\mathrm{a}}$ & $1.13^{\mathrm{a}}$ & $1.07^{\mathrm{b}}$ & $0.10^{\mathrm{b}}$ & $5.70^{\mathrm{b}}$ & $71.37^{\mathrm{d}}$ & $15.50^{\mathrm{b}}$ & $4.52^{\mathrm{a}}$ \\
\hline Z. bisporus & UMCC 61 & $3.17^{\mathrm{a}}$ & $9.75^{\mathrm{a}}$ & $0.86^{\mathrm{ab}}$ & $1.06^{\mathrm{b}}$ & $0.27^{c}$ & $3.49^{\mathrm{a}}$ & $80.41^{\mathrm{d}}$ & $0.02^{\mathrm{a}}$ & $5.94^{\mathrm{b}}$ \\
\hline C. stellata & UMCC 122 & $3.15^{\mathrm{a}}$ & $9.90^{\mathrm{a}}$ & $0.76^{a b c}$ & $0.37^{\mathrm{a}}$ & $0.34^{\text {cd }}$ & $6.19^{b}$ & $53.08^{\mathrm{c}}$ & $0.0^{\mathrm{a}}$ & $8.31^{\mathrm{c}}$ \\
\hline S. ludwigii & UMCC 294 & $3.22^{\mathrm{bc}}$ & $9.59^{\mathrm{a}}$ & $0.44^{c}$ & $0.61^{\mathrm{a}}$ & $0.45^{d}$ & $3.80^{\mathrm{a}}$ & $0.11^{\mathrm{a}}$ & $2.54^{\mathrm{a}}$ & $10.80^{\mathrm{d}}$ \\
\hline S. ludwigii & UMCC 297 & $3.18^{\mathrm{ab}}$ & $9.83^{\mathrm{a}}$ & $0.36^{c}$ & $0.86^{\mathrm{b}}$ & $0.30^{\text {cd }}$ & $4.61^{\mathrm{a}}$ & $0.01^{\mathrm{a}}$ & $3.28^{\mathrm{a}}$ & $10.77^{\mathrm{d}}$ \\
\hline S. cerevisiae & UMCC 855 & $3.19^{\mathrm{abc}}$ & $8.20^{\mathrm{b}}$ & $0.46^{\mathrm{bc}}$ & $0.45^{\mathrm{a}}$ & $0.08^{\mathrm{ab}}$ & $3.53^{\mathrm{a}}$ & $0.02^{\mathrm{a}}$ & $0.16^{\mathrm{a}}$ & $11.06^{\mathrm{d}}$ \\
\hline
\end{tabular}

*Titratable acidty (TA) is expressed as $\mathrm{g} / \mathrm{L}$ of tartaric acid. Values are the means of three replicas. Different letters in superscript denote statistically significant difference. LSD test, $\alpha=0.05$. 


\section{Acetic acid fermentation- base wine inoculated with UMCC 1754 starter culture}

The acetic acid fermentation of the BW from the previous step was carried out in three wood barrels of $60 \mathrm{~L}$ inoculated with the starter culture produced from A. pasteurianus UMCC 1754. The composition of the UMCC 1754 starter culture and of the BW after inoculation is reported in Table 3. The acetic acid fermentation process consisted of two parts. In the first one the concentration of ethanol was higher than $1.0 \mathrm{~g} / \mathrm{L}$ and titratable acidity increased due the production of acetic acid, while the production of gluconate was negligible (Figure 1 and Table 4). In the second part the ethanol concentration decreased until complete depletion and the concentration of gluconate increased at the glucose's expense. In fact, the daily productivity of gluconate was $0.238 \mathrm{~g} \mathrm{~L}^{-1 / d a y}$ and $1.329 \mathrm{gL}^{-1 / d a y}$ in the first and the second part of the fermentation,

Table 2. Sugars and ethanol amount after fermentation of medium M2 (400 g/L of sugars), by Saccharomycodes ludwigii strains.

\begin{tabular}{|c|c|c|c|c|c|c|}
\hline & \multicolumn{2}{|c|}{ Residual sugars (g/L)* } & \multicolumn{2}{|c|}{ Consumed sugars $(\%)^{*}$} & \multirow{2}{*}{ Total residual sugars $(\mathrm{g} / 100 \mathrm{~mL}) *$} & \multirow[t]{2}{*}{ Ethanol ${ }^{\circ} \%(v / v)$} \\
\hline & Glucose & Fructose & Glucose & Fructose & & \\
\hline M2 & 207.7 & 207.8 & - & - & & \\
\hline UMCC 294 & $127.9( \pm 3.36)$ & $157.5( \pm 3.73)$ & $38.44( \pm 16.16)$ & $24.23( \pm 17.95)$ & $39.98( \pm 21.68)$ & $3.8 \pm(2.50)$ \\
\hline UMCC 297 & $111.8( \pm 0.99)$ & $146.1( \pm 1.90)$ & $46.18( \pm 4.78)$ & $29.72( \pm 9.11)$ & $44.33( \pm 11.00)$ & $4.6 \pm(0.80)$ \\
\hline
\end{tabular}

*Data are the average of three independent replicas ( \pm St. Dev.); ${ }^{\circ}$ Values calculated as theoretical ethanol $=$ (sugar consumed expressed as concentration) $\mathrm{x} 0.6$.

Table 3. Basic composition of the starting material for each fermentation step.

\begin{tabular}{lcccc} 
& Cooked must (MB) & Base wine & UMCC 1754 starter culture & Inoculated base wine \\
$\mathrm{pH}$ & $3.46( \pm 0.03)$ & $3.45( \pm 0.05)$ & $3.37( \pm 0.04)$ & $3.44( \pm 0.02)$ \\
Titratable acidity* & $1.50( \pm 0.05)$ & $1.53( \pm 0.07)$ & $60.02( \pm 0.08)$ & $30.03( \pm 0.05)$ \\
\hline Ethanol \% $(\mathrm{v} / \mathrm{v})$ & 0 & $6.35( \pm 0.12)$ & $1.22( \pm 0.10)$ & $3.83( \pm 0.11)$ \\
${ }^{\circ}$ Brix & 34.40 & 27.45 & 20.70 & 25.20 \\
\hline Glucose $(\mathrm{g} / \mathrm{L})$ & $168.40( \pm 12.10)$ & $97.10( \pm 10.12)$ & $71.30( \pm 11.20)$ & $84.18( \pm 8.29)$ \\
Fructose $(\mathrm{g} / \mathrm{L})$ & $155.80( \pm 13.00)$ & $118.50( \pm 12.30)$ & $113.60( \pm 11.22)$ & $115.80( \pm 14.12)$ \\
\hline
\end{tabular}

The values are the average of three independent replica $\left( \pm\right.$ St. Dev). ${ }^{*}$ Titratable acidity expressed as acetic acid $(\mathrm{g} / \mathrm{L})$.

Table 4. First stage of acetic acid fermentation in presence of ethanol.

\begin{tabular}{|c|c|c|c|c|c|}
\hline & Days of fermentation & pH & Titratable acidity (g/L)* & Ethanol \%(v/v) & ${ }^{\circ}$ Brix \\
\hline Inoculated BW & 0 & $3.44( \pm 0.05)$ & $30.3( \pm 0.07)$ & $3.83( \pm 0.75)$ & 25.2 \\
\hline Barrel A & 7 & $3.43( \pm 0.04)$ & $41.4( \pm 0.08)$ & $2.88( \pm 0.60)$ & 24.4 \\
\hline Barrel B & 7 & $3.41( \pm 0.05)$ & $40.1( \pm 0.06)$ & $2.95( \pm 0.58)$ & 24.6 \\
\hline Barrel C & 7 & $3.42( \pm 0.03)$ & $42.0( \pm 0.05)$ & $2.80( \pm 0.38)$ & 24.5 \\
\hline Barrel A & 36 & $3.20( \pm 0.01)$ & $60.0( \pm 0.09)$ & $0.14( \pm 0.05)$ & n.d. \\
\hline Barrel B & 36 & $3.21( \pm 0.04)$ & $60.3( \pm 0.08)$ & $0.21( \pm 0.06)$ & n.d \\
\hline Barrel C & 36 & $3.22( \pm 0.06)$ & $59.7( \pm 0.07)$ & $0.26( \pm 0.03)$ & n.d \\
\hline
\end{tabular}

*Data are the average of three independent replicas ( \pm St. Dev.); titratable acidity expressed as acetic acid. BW, base wine; n.d., not detected.

Table 5. Second stage of acetic fermentation in restricted ethanol content.

\begin{tabular}{|c|c|c|c|c|c|c|c|c|c|c|c|c|c|c|c|}
\hline $\begin{array}{l}\text { Days of } \\
\text { fermentation } \\
(\mathrm{g} / \mathrm{L})\end{array}$ & $\begin{array}{l}\text { Residual } \\
\text { Glucose } \\
(\mathrm{g} / \mathrm{L})\end{array}$ & $\begin{array}{l}\text { Residual } \\
\text { Fructose } \\
(\mathrm{g} / \mathrm{L})\end{array}$ & $(\mathrm{g} / \mathrm{L})$ & $\begin{array}{l}\text { Acetic } \\
\text { Acid } \\
(\mathrm{mg} / \mathrm{L})\end{array}$ & $(g / L)$ & $(g / L)$ & $\begin{array}{l}\text { Gluconic } \\
\text { acid } \\
(\mathrm{g} / \mathrm{L})\end{array}$ & $\begin{array}{l}\text { Glucono- } \\
\text { 8-lactone } \\
\text { (g/L) }\end{array}$ & $\begin{array}{l}\text { L-Malic } \\
\text { acid } \\
(\mathrm{g} / \mathrm{L})\end{array}$ & $\begin{array}{l}\text {-Lactic } \\
\text { acid } \\
(\mathrm{g} / \mathrm{L})\end{array}$ & $\begin{array}{l}\text { L-Lactic } \\
\text { acid } \\
\mathrm{mM}\end{array}$ & $\begin{array}{l}\text { Glucose } \\
\text { consumed } \\
\text { mM }\end{array}$ & $\begin{array}{c}\text { Total } \\
\text { Gluconate* } \\
\text { mM \% }\end{array}$ & $\begin{array}{c}\text { Gluconate } \\
\text { yield }^{\circ} \\
\text { weight \% }\end{array}$ & yield ${ }^{\#}$ \\
\hline & $\begin{array}{l}72.00 \\
( \pm 12.12)\end{array}$ & $\begin{array}{c}94.67 \\
( \pm 8.33)\end{array}$ & $\begin{array}{c}11.73 \\
( \pm 2.23)\end{array}$ & $\begin{array}{c}35.16 \\
( \pm 7.18)\end{array}$ & $\begin{array}{c}0.09 \\
( \pm 0.02)\end{array}$ & $\begin{array}{c}8.24 \\
( \pm 0.21)\end{array}$ & $\begin{array}{c}1.51 \\
( \pm 0.09)\end{array}$ & $( \pm 0.29)$ & $\begin{array}{c}4.28 \\
( \pm 0.51)\end{array}$ & $\begin{array}{c}0.08 \\
( \pm 0.05)\end{array}$ & $( \pm 0.03)$ & n.d. & n.d. & & \\
\hline & $( \pm 11.10)$ & $\begin{array}{c}94.93 \\
( \pm 8.02)\end{array}$ & $\begin{array}{c}8.07 \\
( \pm 1.37)\end{array}$ & $\begin{array}{c}43.01 \\
( \pm 10.51)\end{array}$ & $\begin{array}{c}0.09 \\
( \pm 0.03)\end{array}$ & $\begin{array}{c}8.42 \\
( \pm 0.29)\end{array}$ & $\begin{array}{c}2.01 \\
( \pm 0.04)\end{array}$ & & $\begin{array}{c}4.18 \\
( \pm 0.66)\end{array}$ & $\begin{array}{c}0.07 \\
( \pm 0.04)\end{array}$ & $\begin{array}{c}0.14 \\
( \pm 0.02)\end{array}$ & $\begin{array}{r}17 . \\
( \pm 5\end{array}$ & $\pm 3.18)$ & & \\
\hline & $( \pm 10.30)$ & $\begin{array}{c}95.63 \\
( \pm 8.28)\end{array}$ & $\begin{array}{c}3.59 \\
( \pm 0.77)\end{array}$ & $\begin{array}{c}47.52 \\
( \pm 12.25)\end{array}$ & $\begin{array}{c}0.08 \\
( \pm 0.02)\end{array}$ & $\begin{array}{c}8.19 \\
( \pm 0.10)\end{array}$ & $\begin{array}{c}2.38 \\
( \pm 0.11)\end{array}$ & $\begin{array}{c}13.04 \\
( \pm 0.65)\end{array}$ & $\begin{array}{c}4.19 \\
( \pm 0.51)\end{array}$ & $\begin{array}{c}0.11 \\
( \pm 0.04)\end{array}$ & 0.1 & & $\begin{array}{c}22.03 \\
( \pm 3.82)\end{array}$ & & 3) \\
\hline & $\begin{array}{l}59.52 \\
( \pm 5.38)\end{array}$ & $\begin{array}{c}94.61 \\
( \pm 7.47)\end{array}$ & $\begin{array}{c}1.00 \\
( \pm 0.07)\end{array}$ & $\begin{array}{c}51.73 \\
( \pm 14.29)\end{array}$ & $\begin{array}{c}0.07 \\
( \pm 0.04)\end{array}$ & $\begin{array}{c}7.70 \\
( \pm 0.61)\end{array}$ & $\begin{array}{c}3.06 \\
( \pm 0.03)\end{array}$ & $\begin{array}{c}19.04 \\
( \pm 2.59)\end{array}$ & $\begin{array}{c}4.07 \\
( \pm 0.29)\end{array}$ & $\begin{array}{c}0.08 \\
( \pm 0.02)\end{array}$ & $\begin{array}{c}0.14 \\
( \pm 0.02)(\end{array}$ & $\begin{array}{r}69 . \\
\pm 37\end{array}$ & $\begin{array}{c}52.62 \\
( \pm 12.95) \\
\end{array}$ & $\begin{array}{r}83 \\
( \pm 2 \\
\end{array}$ & $\begin{array}{r}93 . \\
( \pm 26\end{array}$ \\
\hline & $\begin{array}{l}42.40 \\
( \pm 7.37)\end{array}$ & $\begin{array}{c}94.54 \\
( \pm 8.86)\end{array}$ & $\begin{array}{c}0.03 \\
( \pm 0.01)\end{array}$ & $\begin{array}{c}47.94 \\
( \pm 17.61)\end{array}$ & $\begin{array}{c}0.07 \\
( \pm 0.01)\end{array}$ & $\begin{array}{c}5.27 \\
( \pm 0.59)\end{array}$ & $\begin{array}{c}4.32 \\
( \pm 0.38)\end{array}$ & $\begin{array}{c}39.18 \\
( \pm 3.47)\end{array}$ & $\begin{array}{r}4.26 \\
( \pm 0.18\end{array}$ & $\begin{array}{c}0.25 \\
( \pm 0.01)\end{array}$ & $\begin{array}{l}0.21 \\
\pm 0.06)(\end{array}$ & $\begin{array}{r}164 \\
( \pm 27\end{array}$ & $\begin{array}{c}155.28 \\
( \pm 18.01)\end{array}$ & $\begin{array}{c}94.96 \\
( \pm 5.12)\end{array}$ & $\begin{array}{c}102.75 \\
( \pm 4.50)\end{array}$ \\
\hline 2 & $\begin{array}{l}26.56 \\
( \pm 4.70)\end{array}$ & $\begin{array}{c}94.67 \\
( \pm 8.91)\end{array}$ & $\begin{array}{c}0.04 \\
( \pm 0.02)\end{array}$ & $\begin{array}{c}26.98 \\
( \pm 5.38)\end{array}$ & $\begin{array}{c}0.07 \\
( \pm 0.01)\end{array}$ & $\begin{array}{c}4.55 \\
( \pm 0.94)\end{array}$ & $\begin{array}{c}6.64 \\
( \pm 0.73)\end{array}$ & $\begin{array}{c}54.85 \\
( \pm 7.04)\end{array}$ & $\begin{array}{c}3.76 \\
( \pm 0.85)\end{array}$ & $\begin{array}{c}0.36 \\
( \pm 0.09)\end{array}$ & $\begin{array}{c}0.28 \\
( \pm 0.05)(\end{array}$ & $\begin{array}{c}252.45 \\
( \pm 41.34)\end{array}$ & $\begin{array}{c}235.17 \\
( \pm 35.39)\end{array}$ & $\begin{array}{c}93.29 \\
( \pm 2.26)\end{array}$ & $\begin{array}{c}101.51 \\
( \pm 1.03)\end{array}$ \\
\hline
\end{tabular}

Acetaldeh, acetaldehyde; Glycer, glycerol, n.d., not detected. ${ }^{*}$ Gluconic acid + glucono- $\delta$-lactone; ${ }^{\circ}$ (Total gluconate formed)/(glucose consumed) (expressed in mM)\%; ${ }^{*}$ Total gluconate/glucose consumed (expressed in grams) \%. The values are the average of three independent replica $( \pm$ St. Dev). 
respectively. In brief, the increase of gluconate, which corresponds to a proportional decrease of glucose, occurs substantially after ethanol depletion (Figure 1). After the complete ethanol depletion, both acetic acid and glycerol were further oxidized and their concentration were significantly reduced (Table 5). It is important to underline that the microbial composition at the end of the process is a mixed population of different AAB (data not show); cells of the strain UMCC 1754 were still present together with other $\mathrm{AAB}$ strains. The microbiological investigations performed have not been sufficient to define the further occurring species, but only the presence of AAB different from the inoculated strain. This observation does not affect the fact that the glucose is oxidized to gluconate only after the exhaustion of ethanol and, in the meantime, do not exclude that other $\mathrm{AAB}$ are responsible of the glucose oxidation together with the strain UMCC 1754.

Through the overall process, from cooked must to base vinegar, the glucose/fructose ratio decreased from 1.08 to 0.28 , titratable acidity increases from 1.5 to 6.06 (data not shown), $\mathrm{pH}$ decreases from 3.46 to 3.18 (data not shown). The final titratable acidity mostly depends on the presence of gluconic acid and glucono- $\delta$-lactone, whose concentration is two-fold that of acetic acid (Table 5).

The reduction of glucose concentration does not perfectly match the amount of gluconate produced (Table 5), because the fermentation barrels were open and permeable to vapor, leading to the overall concentration of the solutes. The solvent loss induces the overestimation of the glucose/gluconate couple at the end of fermentation, and then the underestimation of the oxidized glucose. Therefore, the yield of gluconate per mole of fermented glucose is higher than the real one and in some replicas is even more than $100 \%$. Although evaporation phenomena partly compromise the yield of gluconate, the general trend of the trials is not affected.

\section{Conclusions}

Titratable acidity, volatile acidity, total sugars concentration and their reciprocal ratio are very important parameters affecting the sensory properties and the physical stability of vinegar..$^{33}$ For these reasons is necessary to control all the parameters of the production process, with the purpose of obtaining the vinegar with the desired characteris-

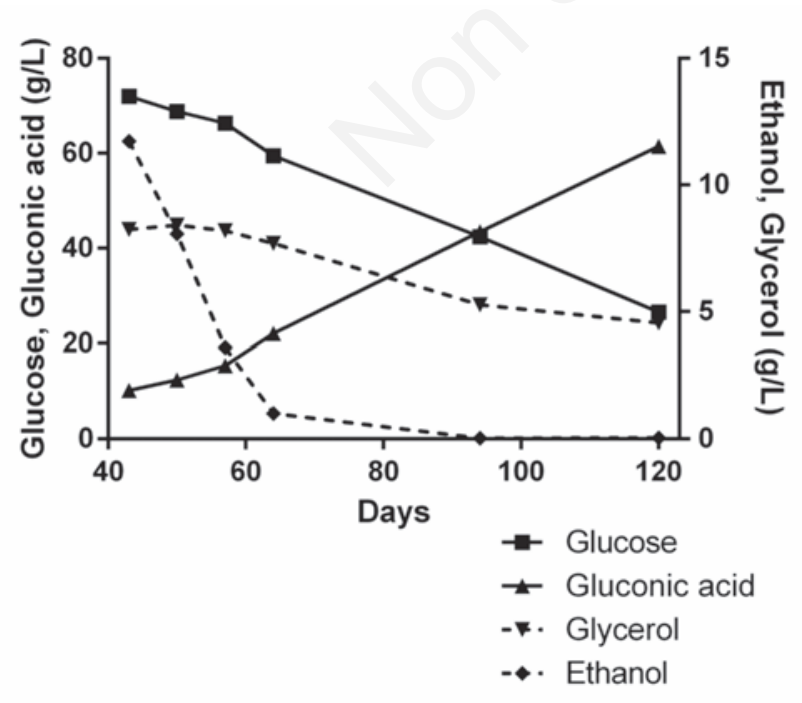

Figure 1. Evolution of the four main compounds during the second part of acetic acid fermentation, when ethanol is lower than $1.0 \mathrm{~g} / \mathrm{L}$. Gluconic acid is the sum of the acid and lactone forms. tics. Both the strains used in fermentation indicate that the guidance of the acetic fermentation plays a fundamental role in defining the composition of the vinegar. In particular, the glucose/fructose ratio can be shifted in favor of the latter by the use of glucosofilic yeasts, and let go of the acetic fermentation for a long time, over the complete depletion of ethanol.

Indeed, without ethanol as carbon source, some $\mathrm{AAB}$ oxidizes glucose to gluconic acid causing the increase of titratable acidity. Gluconic acid has three important implications: i) its pKa is lower than that of acetic acid and therefore it contributes significantly to lower the $\mathrm{pH}$, whose lower values are associated with high quality TBV; 33 ii) it is a non-volatile acid and therefore it increases the fixed acidity of the vinegar without increasing the sensation of pungency like the acetic acid; iii) its taste is acid but mild sweet also, and therefore it contributes to the sensory complexity of the vinegar. In vinegar with equivalent titratable acidity, those rich in gluconic acid are perceived less pungent and generally more appreciated by consumers. In conclusion, the reduction of glucose concentration in the final vinegar product gives two highly positive attributes: a greater physical stability and a greater preference by consumers.

\section{References}

1. Giudici P, Lemmetti F, Mazza S. Traditional balsamic vinegar as coded by us. In: Balsamic vinegars: tradition, technology, trade. Springer International Publishing AG Switzerland; 2015. pp 85-110.

2. Giudici P, Gullo M, Solieri L, Falcone PM. Technological and microbiological aspects of Traditional Balsamic Vinegar and their influence on quality and sensorial properties. Adv Food Nutr Res 2009;58:137-82.

3. Falcone PM, Mozzon M, Frega NG. Structure-composition relationships of the traditional balsamic vinegar of Modena close to jamming transition (part II): Threshold control parameters. Food Res Int 2012;45:75-84.

4. Giudici P, Pulvirenti A, De Vero L, Landi S. Cristallizzazione dell'aceto balsamico tradizionale. Industrie delle bevande 2004;193;426-9.

5. Falcone PM, Tagliazucchi D, Verzelloni E, Giudici P. Sugar conversion induced by the application of heat to grape must. J Agric Food Chem 2010;58:8680-91.

6. Falcone PM, Boselli E, Frega NG. Structure-composition relationships of the traditional balsamic vinegar close to jamming transition. Food Res Int 2011;44:1613-9.

7. Giudici P, Lemmetti F, Mazza S. The ageing of balsamic: residence time, maturity and yeald. In: Balsamic vinegars: tradition, technology, trade. Springer International Publishing AG Switzerland; 2015. pp 143-62.

8. Solieri L, Giudici P. Yeasts associated to Traditional Balsamic Vinegar: ecological and technological features. Int J Food Microbiol 2008; 125:36-45.

9. Solieri L, Landi S, De Vero L, Giudici P. Molecular assessment of indigenous yeast population from traditional balsamic vinegar. J Appl Microbiol 2006;101:63-71.

10. Solieri L, Gullo M, Giudici P. Traditional balsamic vinegar: a microbiological overview. In: Hui YH, Özgül Evranuz E, eds. Handbook of plant-based fermented food and beverage technology, 2nd ed. New York: CRC Press, Taylor and Francis Group; 2012. pp. 609-30.

11. Emmerich W, Radler F. The anaerobic metabolism of glucose and fructose by Saccharomyces bailii. Microbiol 1983;129:3311-18.

12. Sousa-Dias S, Gonçalves T, Leyva JS, et al. Kinetics and regulation of fructose and glucose transport systems are responsible for fructophily in Zygosaccharomyces bailii. Microbiol 1996;142:1733-8. 
13. Pina C, Gonçalves P, Prista C, Loureiro-Dias MC. Ffzl, a new transporter specific for fructose from Zygosaccharomyces bailii. Microbiol 2004;150:2429-33.

14. Leandro MJ, Sychrová H, Prista C, Loureiro-Dias MC. The osmotolerant fructophilic yeast Zygosaccharomyces rouxii employs two plasma-membrane fructose uptake systems belonging to a new family of yeast sugar transporters. Microbiol 2011;157:601-8.

15. Leandro MJ, Fonseca C, Gonçalves P. Hexose and pentose transport in ascomycetous yeasts: an overview. FEMS Yeast Res 2009;9:51125.

16. Lemmetti F, Giudici P. Bilancio di massa ed età dell'Aceto Balsamico Tradizionale. Industrie delle Bevande 2010;39:18-28.

17. De Vero L, Gullo M, Giudici P. Acetic Acid Bacteria, Biotechnological Applications. In: Encyclopedia of Industrial Biotechnology: Bioprocess, Bioseparation, and Cell Technology. Flickinger MC, editor. John Wiley \& Sons, Inc. 2010. pp. 1-17.

18. Giudici P. Acido gluconico: criterio di genuinità dell'aceto balsamico tradizionale. Industrie delle Bevande 1993;124:123-5.

19. Adachi 0, Moonmangmee D, Toyama H, et al. New developments in oxidative fermentation. Appl Microbiol Biotechnol 2003;60:643-53.

20. Matsushita K, Toyama H, Adachi 0 . Respiratory chains in acetic acid bacteria: membrane bound periplasmic sugar and alcohol respirations. In: Respiration in Archaea and Bacteria: diversity of prokaryotic systems. Zannoni D, editor. Springer, Netherlands; 2004. pp 81-99.

21. Deppenmeier U, Hoffmeister M, Prust C. Biochemistry and biotechnological applications of Gluconobacter strains. Appl Microbiol Biotechnol 2002;60:233-42.

22. Matsushita K, Toyama H, Adachi 0 . Respiratory chain and bioenergetics of acetic acid bacteria. In: Advances in microbial physiology, vol 36. Rose AH, Tempest DW, eds, Academic Press, London; 1994. pp 247-301.
23. Weenk G, Olijve W, Harder W. Ketogluconate formation by Gluconobacter species. Appl Microbiol Biotechnol 1984;20:400-5.

24. Giudici P, Masini G. Produzione di acido gluconico da ceppi Acetobacter e Gluconobacter in mosto d'uva. Ann Microbiol Enzimol 1995;45:313-9.

25. Gobbi M, De Vero L, Solieri L, et al. Fermentative aptitude of nonSaccharomyces wine yeast for reduction in the ethanol content in wine. Eur Food Res and Technol 2014;239:41-8.

26. Mezzetti F, De Vero L, Giudici P. Evolved Saccharomyces cerevisiae wine strains with enhanced glutathione production obtained by an evolution-based strategy. FEMS Yeast Res 2014;14:977-87.

27. Bonciani T, Solieri L, De Vero L, Giudici P. Improved wine yeasts by direct mating and selection under stressful fermentative conditions. Eur Food Res Technol 2016;242:899-910.

28. Gullo M, De Vero L, Giudici P. Succession of selected strains of Acetobacter pasteurianus and other acetic acid bacteria in traditional balsamic vinegar. Appl Environ Microbiol 2009;75:2585-9.

29. Gullo M, Mamlouk D, De Vero L, Giudici P. Acetobacter pasteurianus Strain AB0220: Cultivability and Phenotypic Stability Over 9 Years of Preservation. Curr Microbiol 2012;64:576-80.

30. Lane JH, Eynon L. Determination of reducing sugars by means of Fehling's solution with methylene blue as internal indicator. J Soc Chem Ind Trans 1923:32-6.

31. De Ley J, Kersters K. Oxidation of aliphatic glycols by acetic acid bacteria. Bacteriol Rev 1964;28:164-80.

32. Thomas D, Davenport RR. Zygosaccharomyces bailii: a profile of characteristics and spoilage activities. Food Microbiol 1985;2:15769.

33. Giudici P, Lemmetti F, Mazza S. Sensorial properties and evaluation of balsamic vinegars. In: Balsamic vinegars: tradition, technology, trade. Springer International Publishing AG Switzerland; 2015. pp $111-40$. 